\title{
HYGROSCOPICALLY INDUCED RESIDUAL STRESSES IN COMPOSITE LAMINATES
}

\author{
Tran Ich Thinh*, Ngo NhU KHOA** \\ * Hanoi University of Technology \\ ** Thainguyen Industrial and Technical University
}

\begin{abstract}
In this paper the exact moisture concentration function $m(z, t)$ is used to compute the hygroscopic residual stresses in laminated composites. The governing equations were established by using a full higher-order displacement theory. Hygroscopically induced residual stresses in thick graphite-epoxy composite laminates: Cross-ply $[0 / 90]_{s}$ based on this approach were compared with those obtained by assumption: the moisture concentration $m$ is a constant in all plies through the laminates thickness.
\end{abstract}

\section{Introduction}

When an organic matrix composite is exposed to humid air or to a liquid, the moisture content of the material may change with time. These changes, in turn, affect the decrease in performance of materials [1]. To utilise the full potential of composite materials and structures, their response to hygroscopic environment must be known.

Investigations of such problems have been performed by Pipes, Vinson and Chou $[1,2]$. Ootao et al [3] have used the Laplace transform, method of separation of variables with the classical laminated plate theory to asses the transient stress fields in multilayered anisotropic, laminated slabs. An interesting approach has been recently presented by Benkeddad [4] for the transient absorption of moisture in thin laminated plates. Each ply is divided into "supplies" and the exact moisture concentration distribution is approached by linear segments, thank to a finite difference method. Paul and Vautrin [5] studied hygrothermal stresses in thick laminated cylinders by analytical method, the moisture distribution is approached through a finite difference method.

The classical laminated theories are probably the most dominant mainly because they have produced satisfactory results for global analysis of thin laminated composites. However, for thick or moderately thick laminated composites, these theories give poor results because they do not precisely model kinemetic configurations of the laminated composites. Besides, they do not provide meaningful predictions of transverse and interlaminar stresses.

The present studies are different from previous studies in that:

- The full third-order theory is used, in which both in-plane and out-of-plane 
displacement components are assumed to have cubic variations through the thickness of the plate.

- The laminate moisture concentration distribution $m(z, t)$ is a true representation of a practical situation.

By using the software developed, some numerical results, focusing on hygroscopic residual stresses are presented.

\section{Hygroscopic diffusion mechanism}

The Fick equation of diffusion is used to determine the laminate moisture concentration distribution $[1,2]$ :

$$
\frac{\partial m}{\partial t}=D_{z} \frac{\partial^{2} m}{\partial z^{2}}
$$

where $m$ is moisture concentration; $t$ - time; $z$ - distance through laminate thickness; $D_{z}$ - mass diffusity constant through the laminate's thickness.

The moisture concentration $m$ as a function of position $z$ and time $t$ is [2]:

$$
\frac{m-m_{i}}{m_{s}-m_{i}}=1-\frac{4}{\pi} \sum_{j=0}^{\infty} \frac{(-1)^{j}}{2 j+1} \cos \frac{(2 j+1) \pi z}{h} \exp \frac{-(2 j+1)^{2} \pi^{2} D_{z} t}{h^{2}},
$$

where $m_{i}$ is the uniform, initial moisture concentration inside the material $(t=0)$, $m_{s}$ is the maximum moisture concentration that is reach in the material for a given ambient condition, $h$ is the laminate's thickness.

If the laminate is assumed to be initially dry $\left(m_{i}=0\right.$ when $t=0$, at all $z$ ), while its surface $z= \pm h / 2$ are exposed to a moisture concentration $m_{s}$, then moisture concentration in the laminate at position $z$ and time $t$ is

$$
m(z, t)=m_{s}\left[1-\sum_{n=0}^{\infty} a_{n} \cos \left(b_{n} z\right)\right]
$$

where $a_{n}=\frac{4}{\pi}\left\{\frac{(-1)^{n}}{2 n+1} \exp \left[-b_{n}^{2} D_{z} t\right]\right\}, b_{n}=\frac{(2 n+1) \pi}{h}$.

In practice, it is much easier to determine, by simple weight measurements, the total amount of moisture by weight rather the actual concentration in a laminate. The amount of moisture by weight in a laminate is usually expressed in percentage terms:

$$
M(\%)=\frac{\text { weight of moisture in laminate }}{\text { weight of dry laminate }} \times 100 .
$$

3. Hygroscopic force and moment resultants

Refering to the principal material coordinates axes (1-2-3) and reference axes 
$(x-y-z)$ of $k^{\text {th }}$ orthotropic layer, the hygroscopic residual stresses can be written as $[6,7,11]$ :

$$
\begin{gathered}
\left\{\begin{array}{l}
\sigma_{11} \\
\sigma_{22} \\
\sigma_{33} \\
\sigma_{23} \\
\sigma_{13} \\
\sigma_{12}
\end{array}\right\}_{k}=\left[\begin{array}{cccccc}
C_{11} & C_{12} & C_{13} & 0 & 0 & 0 \\
C_{12} & C_{22} & C_{23} & 0 & 0 & 0 \\
C_{13} & C_{23} & C_{33} & 0 & 0 & 0 \\
0 & 0 & 0 & C_{44} & 0 & 0 \\
0 & 0 & 0 & 0 & C_{55} & 0 \\
0 & 0 & 0 & 0 & 0 & C_{66}
\end{array}\right]_{k}\left\{\begin{array}{c}
\varepsilon_{11}-\varepsilon_{11}^{M} \\
\varepsilon_{22}-\varepsilon_{22}^{M} \\
\varepsilon_{33}-\varepsilon_{33}^{M} \\
\gamma_{23} \\
\gamma_{13} \\
\gamma_{12}
\end{array}\right\}_{k} \\
\left\{\begin{array}{l}
\sigma_{x x} \\
\sigma_{y y} \\
\sigma_{z z} \\
\sigma_{y z} \\
\sigma_{x z} \\
\sigma_{x y}
\end{array}\right\}_{k}=\left[\begin{array}{cccccc}
C_{11}^{\prime} & C_{12}^{\prime} & C_{13}^{\prime} & 0 & 0 & C_{16}^{\prime} \\
C_{12}^{\prime} & C_{22}^{\prime} & C_{23}^{\prime} & 0 & 0 & C_{26}^{\prime} \\
C_{13}^{\prime} & C_{23}^{\prime} & C_{33}^{\prime} & 0 & 0 & C_{36}^{\prime} \\
0 & 0 & 0 & C_{44}^{\prime} & C_{45}^{\prime} & 0 \\
0 & 0 & 0 & C_{54}^{\prime} & C_{55}^{\prime} & 0 \\
C_{16}^{\prime} & C_{26}^{\prime} & C_{36}^{\prime} & 0 & 0 & C_{66}^{\prime}
\end{array}\right]_{k}\left\{\begin{array}{c}
\varepsilon_{x x}-\varepsilon_{x x}^{M} \\
\varepsilon_{y y}-\varepsilon_{y y}^{M} \\
\varepsilon_{z z}-\varepsilon_{z z}^{M} \\
\gamma_{y z} \\
\gamma_{x z} \\
\gamma_{x y}-\gamma_{x y}^{M}
\end{array}\right\}_{k}
\end{gathered}
$$

where $C_{i j}$ and $C_{i j}^{\prime}$ are the stiffness coefficients of material layers in principal coordinate axes $(1-2-3)$ and reference axes $(x-y-z)$ respectively; $\varepsilon_{11}^{M}, \varepsilon_{22}^{M}, \varepsilon_{33}^{M}, \varepsilon_{x x}^{M}, \varepsilon_{y y}^{M}, \varepsilon_{z z}^{M}$, $\gamma_{x y}^{M}$ are the free hygroscopic strains.

The relation between $C_{i j}$ and $C_{i j}^{\prime}$ is expressed by:

$$
\left[C^{\prime}\right]_{k}=\left[T_{\sigma}^{-1}\right]_{k}[C]_{k}\left[T_{\varepsilon}\right]_{k}
$$

and the relation between the stiffness constants and engineering elastic constants are:

$$
\begin{aligned}
& C_{11}=\frac{1-\nu_{23} \nu_{32}}{E_{2} E_{3} \Delta} ; \quad C_{12}=\frac{\nu_{12}+\nu_{32} \nu_{13}}{E_{1} E_{3} \Delta} ; \quad C_{13}=\frac{\nu_{13}+\nu_{12} \nu_{23}}{E_{1} E_{2} \Delta} \\
& C_{22}=\frac{1-\nu_{13} \nu_{23}}{E_{1} E_{3} \Delta} ; \quad C_{23}=\frac{\nu_{23}+\nu_{21} \nu_{13}}{E_{1} E_{2} \Delta} ; \quad C_{33}=\frac{1-\nu_{12} \nu_{21}}{E_{1} E_{2} \Delta} ; \quad C_{44}=G_{23} \\
& C_{55}=G_{13} ; C_{66}=G_{12} ; \Delta=\frac{1-\nu_{12} \nu_{21}-\nu_{23} \nu_{32}-\nu_{13} \nu_{31}-2 \nu_{21} \nu_{32} \nu_{13}}{E_{1} E_{2} E_{3}}
\end{aligned}
$$

$T_{\sigma}^{-1}$ is inverse matrix of stress transformation matrix $T_{\sigma} ; T_{\varepsilon}$ is strain transformation matrix [8].

The free hygroscopic strains in each ply are defined as:

$$
\begin{aligned}
& \left(\varepsilon_{x x}^{M}, \varepsilon_{y y}^{M}, \varepsilon_{z z}^{M}, 0,0, \gamma_{x y}^{M}\right)_{k}^{t}=T_{\varepsilon}\left(\varepsilon_{11}^{M}, \varepsilon_{22}^{M}, \varepsilon_{33}^{M}, 0,0,0\right)_{k}^{t}=T_{\varepsilon}\left(\beta_{11}, \beta_{22}, \beta_{33}, 0,0,0\right)_{k}^{t} m(z, t) \\
& \text { and } \beta_{x x}=\beta_{11} \cos ^{2} \theta+\beta_{22} \sin ^{2} \theta ; \quad \beta_{y y}=\beta_{y y} \cos ^{2} \theta+\beta_{11} \sin ^{2} \theta ; \\
& \quad \beta_{z z}=\beta_{33} ; \quad \beta_{x y}=\left(\beta_{11}-\beta_{22}\right) \sin 2 \theta
\end{aligned}
$$

where " $t$ " signifies matrix transpose; $\beta_{i i}(i=1,2,3)$ are the coefficients of hygroscopic expansion; $m$ is the change in moisture concentration refering to a "moisturefree" environment. 
Based on the general high-order displacement field in which the displacement components $u(x, y, z), v(x, y, z), w(x, y, z)$ and strain components $\left(\varepsilon_{x x}, \varepsilon_{y y}, \varepsilon_{z z}, \gamma_{y z}\right.$, $\left.\gamma_{x z}, \gamma_{x y}\right)$ are of third-order in the thickness coordinate $z([10,11])$ and by integrating the stresses through the plate thickness, we obtained the generalized force-strain relations:

$$
\begin{gathered}
\left\{\begin{array}{c}
\{N\} \\
\{M\} \\
\{S\} \\
\{P\}
\end{array}\right\}+\left\{\begin{array}{l}
\left\{N^{M}\right\} \\
\left\{M^{M}\right\} \\
\left\{S^{M}\right\} \\
\left\{P^{M}\right\}
\end{array}\right\}=\left[\begin{array}{llll}
\mathbf{A} & \mathbf{B} & \mathbf{D} & \mathbf{E} \\
\mathbf{B} & \mathbf{D} & \mathbf{E} & \mathbf{F} \\
\mathbf{D} & \mathbf{E} & \mathbf{F} & \mathbf{G} \\
\mathbf{E} & \mathbf{F} & \mathbf{G} & \mathbf{H}
\end{array}\right]\left\{\begin{array}{l}
\left\{\varepsilon^{0}\right\} \\
\{\mathbf{k}\} \\
\{\chi\} \\
\{\boldsymbol{\eta}\}
\end{array}\right\} \\
\left\{\begin{array}{c}
\{Q\} \\
\{V\} \\
\{R\} \\
\{W\}
\end{array}\right\}=\left[\begin{array}{llll}
\mathbf{A}^{\prime} & \mathbf{B}^{\prime} & \mathbf{D}^{\prime} & \mathbf{E}^{\prime} \\
\mathbf{B}^{\prime} & \mathbf{D}^{\prime} & \mathbf{E}^{\prime} & \mathbf{F}^{\prime} \\
\mathbf{D}^{\prime} & \mathbf{E}^{\prime} & \mathbf{F}^{\prime} & \mathbf{G}^{\prime} \\
\mathbf{E}^{\prime} & \mathbf{F}^{\prime} & \mathbf{G}^{\prime} & \mathbf{H}^{\prime}
\end{array}\right]\left\{\begin{array}{l}
\left\{\boldsymbol{\gamma}^{0}\right\} \\
\left\{\mathbf{k}^{\prime}\right\} \\
\left\{\chi^{\prime}\right\} \\
\left\{\eta^{\prime}\right\}
\end{array}\right\}
\end{gathered}
$$

where

$$
\begin{aligned}
\mathbf{A}, \ldots, \mathbf{H} & =\left[\begin{array}{crrr}
A_{11} & A_{12} & A_{13} & A_{16} \\
& A_{22} & A_{23} & A_{26} \\
(\mathrm{Sym}) & & A_{33} & A_{36} \\
& & A_{66}
\end{array}\right], \ldots,\left[\begin{array}{llll}
H_{11} & H_{12} & H_{13} & H_{16} \\
& H_{22} & H_{23} & H_{26} \\
(\mathrm{Sym}) & & H_{33} & H_{36} \\
& & & H_{66}
\end{array}\right] \\
\mathbf{A}^{\prime}, \ldots, \mathbf{H}^{\prime} & =\left[\begin{array}{ll}
A_{44} & A_{45} \\
A_{45} & A_{55}
\end{array}\right], \ldots,\left[\begin{array}{lll}
H_{44} & H_{45} \\
H_{45} & H_{55}
\end{array}\right]
\end{aligned}
$$

- The coefficients of stiffness matrices are determined by $[10,11]$ :

$$
\left(A_{i j}, B_{i j}, D_{i j}, E_{i j}, F_{i j}, G_{i j}, H_{i j}\right)=\sum_{k=1}^{n} \int_{h_{k-1}}^{h_{k}}\left(C_{i j}^{\prime}\right)_{k}\left(1, z, z^{2}, z^{3}, z^{4}, z^{5}, z^{6}\right) d z
$$

and $\left\{\varepsilon^{0}\right\}=\left(\begin{array}{llll}\varepsilon_{x x}^{0} & \varepsilon_{y y}^{0} & \varepsilon_{z z}^{0} & \gamma_{x y}^{0}\end{array}\right)^{t} ;\{\mathbf{k}\}=\left(k_{x x} k_{y y} k_{z z} k_{x y}\right)^{t} ;\{\chi\}=\left(\chi_{x x} \chi_{y y} \chi_{x z} \chi_{x y}\right)^{t} ;$ $\{\eta\}=\left\{\begin{array}{llll}\eta_{x x} & \eta_{y y} & 0 & \eta_{x y}\end{array}\right)^{t} ;\left\{\boldsymbol{\gamma}^{0}\right\}=\left(\begin{array}{ll}\gamma_{y z}^{0} & \gamma_{x z}^{0}\end{array}\right)^{t} ;\left\{\mathbf{k}^{\prime}\right\}=\left(\begin{array}{lll}k_{y z} & k_{x z}\end{array}\right)^{t} ;\left\{\chi^{\prime}\right\}=\left(\begin{array}{ll}\chi_{y z} & \chi_{x z}\end{array}\right)^{t} ;$ $\left\{\eta^{\prime}\right\}=\left(\eta_{y z} \eta_{x z}\right)^{t}$.

The expressions of these strain components are defined in [10].

- The hygroscopic generalized resultants are determined by:

$$
\begin{aligned}
& \left\{\left\{N^{M}\right\},\left\{M^{M}\right\},\left\{S^{M}\right\},\left\{P^{M}\right\}\right\}= \\
& =\left\{\begin{array}{llll}
N_{x}^{M} & M_{x}^{M} & S_{x}^{M} & P_{x}^{M} \\
N_{y}^{M} & M_{y}^{M} & S_{y}^{M} & P_{y}^{M} \\
N_{z}^{M} & M_{z}^{M} & S_{z}^{M} & P_{z}^{M} \\
N_{x y}^{M} & M_{x y}^{M} & S_{x y}^{M} & P_{x y}^{M}
\end{array}\right\}=\int_{-h / 2}^{h / 2} \sum_{k=1}^{n}\left[C_{i j}^{\prime}\right]_{k}\left[\begin{array}{c}
\beta_{x x} \\
\beta_{y y} \\
\beta_{z z} \\
\beta_{x y}
\end{array}\right] m(z, t)\left(1, z, z^{2}, z^{3}\right) d z .
\end{aligned}
$$


If the mechanical loads are zero, then by inverting the relations (3.4a), (3.4b), we obtaine the laminate generalized common strain field:

$$
\begin{gathered}
\left\{\begin{array}{l}
\left\{\varepsilon^{0}\right\} \\
\{\mathbf{k}\} \\
\{\chi\} \\
\{\boldsymbol{\eta}\}
\end{array}\right\}=\left[\begin{array}{llll}
\mathbf{A} & \mathbf{B} & \mathbf{D} & \mathbf{E} \\
\mathbf{B} & \mathbf{D} & \mathbf{E} & \mathbf{F} \\
\mathbf{D} & \mathbf{E} & \mathbf{F} & \mathbf{G} \\
\mathbf{E} & \mathbf{F} & \mathbf{G} & \mathbf{H}
\end{array}\right]^{-1}\left[\begin{array}{l}
\left\{N^{M}\right\} \\
\left\{M^{M}\right\} \\
\left\{S^{M}\right\} \\
\left\{P^{M}\right\}
\end{array}\right\} \\
\left\{\begin{array}{l}
\left\{\boldsymbol{\gamma}^{0}\right\} \\
\left\{\boldsymbol{k}^{\prime}\right\} \\
\left\{\chi^{\prime}\right\} \\
\left\{\boldsymbol{\eta}^{\prime}\right\}
\end{array}\right\}=\left[\begin{array}{llll}
\mathbf{A}^{\prime} & \mathbf{B}^{\prime} & \mathbf{D}^{\prime} & \mathbf{E}^{\prime} \\
\mathbf{B}^{\prime} & \mathbf{D}^{\prime} & \mathbf{E}^{\prime} & \mathbf{F}^{\prime} \\
\mathbf{D}^{\prime} & \mathbf{E}^{\prime} & \mathbf{F}^{\prime} & \mathbf{G}^{\prime} \\
\mathbf{E}^{\prime} & \mathbf{F}^{\prime} & \mathbf{G}^{\prime} & \mathbf{H}^{\prime}
\end{array}\right]^{-}\left\{\begin{array}{l}
\{Q\} \\
\{V\} \\
\{R\} \\
\{W\}
\end{array}\right\}
\end{gathered}
$$

From equations (2.3) and (3.8), the effective hygroscopic generalized resultants can be readily determined by:

$$
\begin{aligned}
& \left\{\begin{array}{l}
N_{x}^{M} \\
N_{y}^{M} \\
N_{z}^{M} \\
N_{x y}^{M}
\end{array}\right\}=\sum_{k=1}^{n}\left[C_{i j}^{\prime}\right]_{k}\left[\begin{array}{c}
\beta_{x x} \\
\beta_{y y} \\
\beta_{z z} \\
\beta_{x y}
\end{array}\right]_{k} m_{s} \times\left[\left(h_{k}-h_{k-1}\right)-\sum_{n=0}^{\infty} \frac{a_{n}}{b_{n}}\left(\sin \left(b_{n} h_{k}\right)-\sin \left(b_{n} h_{k-1}\right)\right)\right] \\
& \left\{\begin{array}{l}
M_{x}^{M} \\
M_{y}^{M} \\
M_{z}^{M} \\
M_{x y}^{M}
\end{array}\right\}=\sum_{k=1}^{n}\left[C_{i j}^{\prime}\right]_{k}\left[\begin{array}{c}
\beta_{x x} \\
\beta_{y y} \\
\beta_{z z} \\
\beta_{x y}
\end{array}\right]_{k} m_{s} \times\left\{\left[\frac{1}{2}\left(h_{k}^{2}-h_{k-1}^{2}\right)\right.\right. \\
& \left.-\sum_{n=0}^{\infty} \frac{a_{n}}{b_{n}}\left(h_{k} \sin \left(b_{n} h_{k}\right)-h_{k-1} \sin \left(b_{n} h_{k-1}\right)\right)-\sum_{n=0}^{\infty} \frac{a_{n}}{b_{n}^{2}}\left(\cos \left(b_{n} h_{k}\right)-\cos \left(b_{n} h_{k-1}\right)\right)\right\} \\
& \left\{\begin{array}{l}
S_{x}^{M} \\
S_{y}^{M} \\
S_{z}^{M} \\
S_{x y}^{M}
\end{array}\right\}=\sum_{k=1}^{n}\left[C_{i j}^{\prime}\right]_{k}\left[\begin{array}{c}
\beta_{x x} \\
\beta_{y y} \\
\beta_{z z} \\
\beta_{x y}
\end{array}\right]_{k} m_{s} \times\left\{\left[\frac{1}{3}\left(h_{k}^{3}-h_{k-1}^{3}\right)\right.\right. \\
& -\sum_{n=0}^{\infty} \frac{a_{n}}{b_{n}}\left(h_{k}^{2} \sin \left(b_{k} h_{k}\right)-h_{k-1}^{2} \sin \left(b_{n} h_{k-1}\right)\right]-\sum_{n=0}^{\infty} \frac{2 a_{n}}{b_{n}^{2}}\left(h_{k} \cos \left(b_{n} h_{k}\right)-h_{k-1} \cos \left(b_{n} h_{k-1}\right)\right. \\
& \left.+\sum_{n=0}^{\infty} \frac{2 a_{n}}{b_{n}^{3}}\left(\sin \left(b_{n} h_{k}\right)-\sin \left(b_{n} h_{k-1}\right)\right)\right\} \\
& \left\{\begin{array}{l}
P_{x}^{M} \\
P_{y}^{M} \\
P_{z}^{M} \\
P_{x y}^{M}
\end{array}\right\}=\sum_{k=1}^{n}\left[C_{i j}^{\prime}\right]_{k}\left[\begin{array}{c}
\beta_{x x} \\
\beta_{y y} \\
\beta_{z z} \\
\beta_{x y}
\end{array}\right]_{k} m_{s} \times\left\{\left[\frac{1}{4}\left(h_{k}^{4}-h_{k-1}^{4}\right)-\right.\right.
\end{aligned}
$$




$$
\begin{aligned}
& -\sum_{n=0}^{\infty} \frac{a_{n}}{b_{n}}\left(h_{k}^{3} \sin \left(b_{n} h_{k}\right)-h_{k-1}^{3} \sin \left(b_{n} h_{k-1}\right)\right)-\sum_{n=0}^{\infty} \frac{3 a_{n}}{b_{n}^{2}}\left(h_{k}^{2} \cos \left(b_{n} h_{k}\right)-h_{k-1}^{2} \cos \left(b_{n} h_{k-1}\right)\right) \\
& \left.+\sum_{n=0}^{\infty} \frac{6 a_{n}}{b_{n}^{3}}\left(h_{k} \sin \left(b_{n} h_{k}\right)-h_{k-1} \sin \left(b_{n} h_{k-1}\right)\right)+\sum_{n=0}^{\infty} \frac{6 a_{n}}{b_{n}^{4}}\left(\cos \left(b_{n} h_{k}\right)-\cos \left(b_{n} h_{k-1}\right)\right)\right\}
\end{aligned}
$$

In practice, to simplify calculations, moisture content $m$ is usually ass'rned to be constant through the laminate thickness.

\section{Numerical results}

We will look at two examples of the moisture content distribution profiles through the laminate thickness. The first one is assuming that there is a true varying profile of moisture content distribution (equation (2.3)); the second example will consider a constant moisture content distribution.

Example 1. Cross-ply [0/90], graphite/epoxy laminate subjected to $m(z, t)$

The elastic and physical properties of material plies are: $E_{1}=140 \mathrm{GPa} ; E_{2}=$ $E_{3}=10 \mathrm{GPa} ; G_{12}=G_{13}=4.14 \mathrm{GPa} ; G_{23}=3.2 \mathrm{GPa} ; \nu_{12}=\nu_{13}=0.3 ; \nu_{23}=0.46 ;$ $\beta_{11}=0.01 ; \beta_{22}=\beta_{33}=0.3 ; m_{s}=1 \% ; D_{z}=3.9 \times 10^{-8} \mathrm{~mm}^{2} / \mathrm{s} ; t=10.000 \mathrm{~h}$; thickness $h_{k}=0.5 \mathrm{~mm}$.

Based on the equation (2.3), we determined the real moisture concentration distribution profile through the laminate thickness (Fig. 1). The hygroscopic residual stresses in principal (1-2-3) axes at bottom and top surface for each ply of the [0/90 $]_{s}$ laminate are given in Table 1 . Their variations through the laminate thickness are illustrated in Fig. 2-4.

Table 1. Hygroscopic residual stresses $(\mathrm{MPa})$ in the (1-2-3) axes

\begin{tabular}{cccccccc}
\hline Ply & \multirow{2}{*}{\begin{tabular}{c} 
Surface \\
\cline { 1 - 3 } Ply 1
\end{tabular}} & Bottom & Moisture & $\sigma_{1}(\mathrm{MPa})$ & $\sigma_{2}(\mathrm{MPa})$ & $\sigma_{3}(\mathrm{MPa})$ & $\sigma_{13} ; \sigma_{23} ; \sigma_{12}$ \\
\cline { 8 - 9 }$\left(0^{\circ}\right)$ & Top & 0.35 & & -10.937 & -2.564 & 1.436 & 0 \\
Ply 2 & Bottom & 0.35 & 68.291 & -7.545 & -0.313 & 0 \\
$\left(90^{\circ}\right)$ & Top & 0.01 & -27.446 & -1.897 & 0.300 & 0 \\
Ply 3 & Bottom & 0.01 & -27.446 & -1.897 & 0.300 & 0 \\
$\left(90^{\circ}\right)$ & Top & 0.35 & 68.291 & -7.545 & -0.313 & 0 \\
Ply 4 & Bottom & 0,35 & 16.511 & -4.831 & -0.174 & 0 \\
$\left(0^{\circ}\right)$ & Top & 1 & -10.937 & -2.564 & 1.435 & 0 \\
\hline
\end{tabular}


It is seen from Table 1 and Fig. 2-4 that:

- The maximum tensile stress $\sigma_{1}$ is $68.291 \mathrm{MPa}$ and occurs in $90^{\circ}$ plies,

- The maximum compression stress $\sigma_{2}$ is $-7.545 \mathrm{MPa}$ and occurs also in $90^{\circ}$ plies,

- The maximum tensile interlaminar stress is $1.436 \mathrm{MPa}$ and occurs at external surfaces of $0^{\circ}$ plies,

- The shear stresses $\left(\sigma_{13} ; \sigma_{23} ; \sigma_{12}\right)$ are zero for all plies.

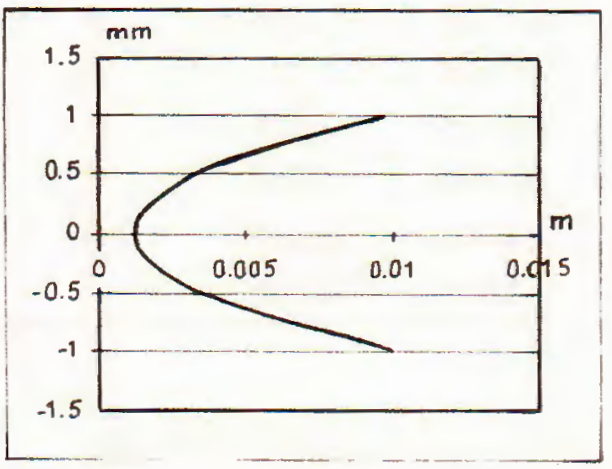

Fig. 1. Real moisture content distribution through $[0 / 90]_{s}$ laminate thickness

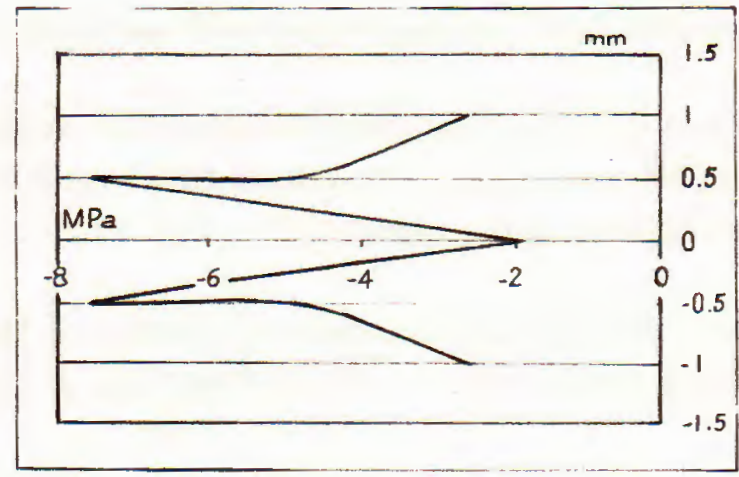

Fig. 3. Hygroscopic residual stresses $\sigma_{2}$ in matrix direction

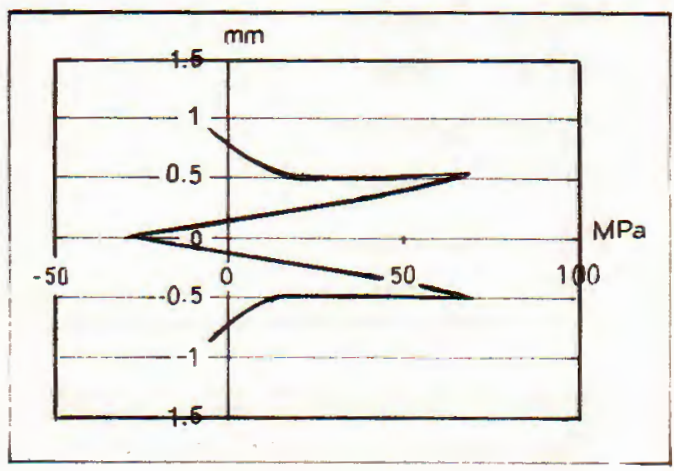

Fig. 2. Hygroscopic residual stresses $\sigma_{1}$ in fibre direction

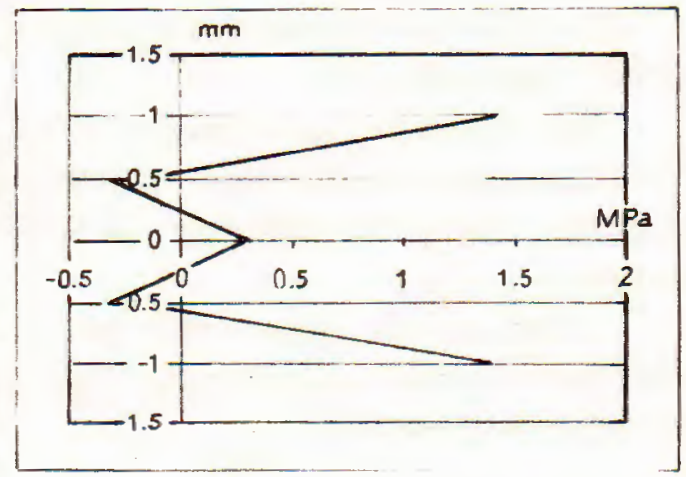

Fig. 4. Hygroscopic residual stresses $\sigma_{3}$ in thickness direction

Example 2. Cross-ply [0/90]. graphite/epoxy laminate subjected to known $m_{s}=1 \%$ in each ply

Consider the same $[0 / 90]_{s}$ laminate configuration as in Example 1, but now subjected to a constant moisture concentration $m_{s}=1 \%$ in all plies through the laminate thickness.

The hygroscopic residual stresses in principal (1-2-3) axes at bottom and top surfaces for each ply of the $[0 / 90]_{s}$ laminate are given in Table 2. Their variations through the laminate thickness are illustrated in Fig. 6-8. 
Table 2. Hygroscopic residual stresses (MPa) in the (1-2-3) axes

\begin{tabular}{|c|c|c|c|c|c|c|}
\hline Ply & Surface & $\%$ Moisture & $\sigma_{1}(\mathrm{MPa})$ & $\sigma_{2}(\mathrm{MPa})$ & $\sigma_{3}(\mathrm{MPa})$ & $\sigma_{13} ; \sigma_{23} ; \sigma_{12}$ \\
\hline Ply 1 & Bottom & 1 & -66.282 & 4.886 & 0.174 & 0 \\
\hline$\left(0^{\circ}\right)$ & Top & 1 & 88.123 & -19.934 & -0.193 & 0 \\
\hline Ply 2 & Bottom & 1 & 95.568 & -20.324 & -0.213 & 0 \\
\hline$\left(90^{\circ}\right)$ & Top & 1 & -34.429 & -19.086 & 0.151 & 0 \\
\hline Ply 3 & Bottom & 1 & -34.429 & -19.086 & 0.151 & 0 \\
\hline$\left(90^{\circ}\right)$ & Top & 1 & 95.568 & -20.324 & -0.213 & 0 \\
\hline Ply 4 & Bottom & 1 & 88.124 & -19.934 & -0.193 & 0 \\
\hline$\left(0^{\circ}\right)$ & Top & 1 & -66.282 & 4.886 & 0.174 & 0 \\
\hline
\end{tabular}

We see from Table 2 and Fig. 6-8 that:

- The maximum tensile stress $\sigma_{1}$ is $95.568 \mathrm{MPa}$ and occurs in $90^{\circ}$ plies,

- The maximum compression stress $\sigma_{2}$ is $-20.324 \mathrm{MPa}$ and occurs also in $90^{\circ}$ plies,

- The shear stresses $\left(\sigma_{13} ; \sigma_{23} ; \sigma_{12}\right)$ are zero for all plies.

From the summary of the obtained results, we see that:

- Moisture absorption produces the considerable residual stresses in each ply of $[0 / 90]_{s}$ laminate.

- The residual stresses components $\sigma_{1}$ and $\sigma_{2}$ in the considered laminate subjected to a constant moisture concentration ( $m=1 \%$ in all plies) are systematically greater than the same components in the same laminate, but subjected to a real moisture content $m(z, t)$.

- Although the hygroscopic residual stresses in the transverse direction of the plies are of small magnitudes, they are of significance as the corresponding ply strengths are also low.

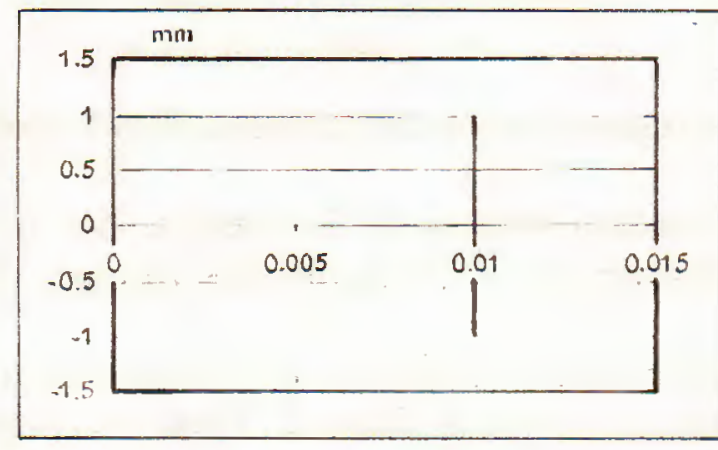

Fig. 5. Constant moisture content distribution through $[0 / 90]_{s}$ laminate thickness

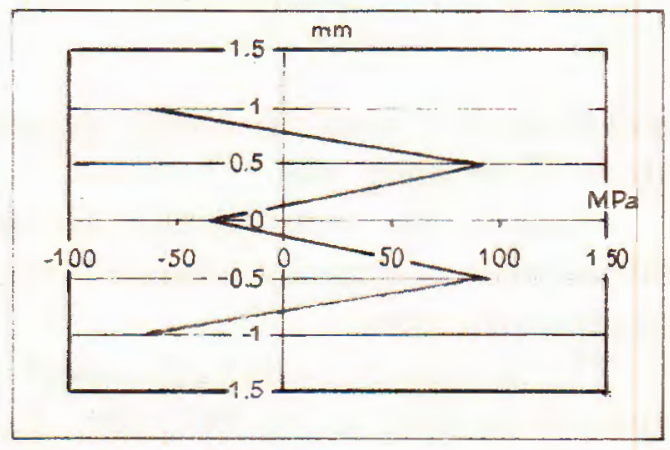

Fig. 6. Hygroscopic residual stresses $\sigma_{1}$ in fibre direction 


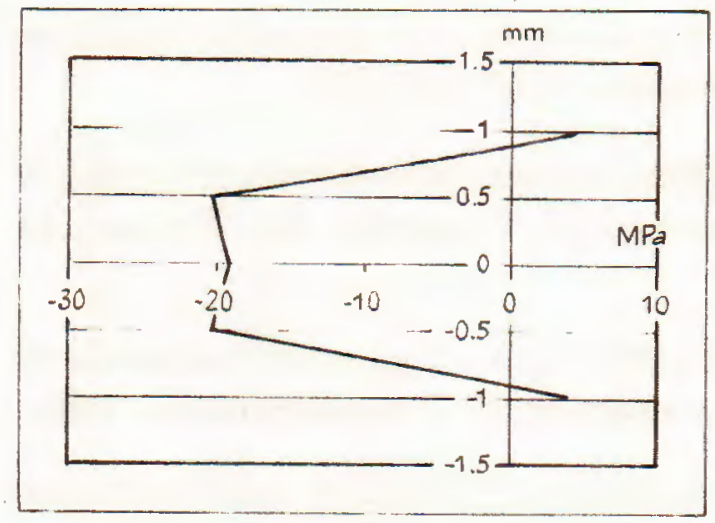

Fig. \%. Hygroscopic residual stresses $\sigma_{2}$ in matrix direction

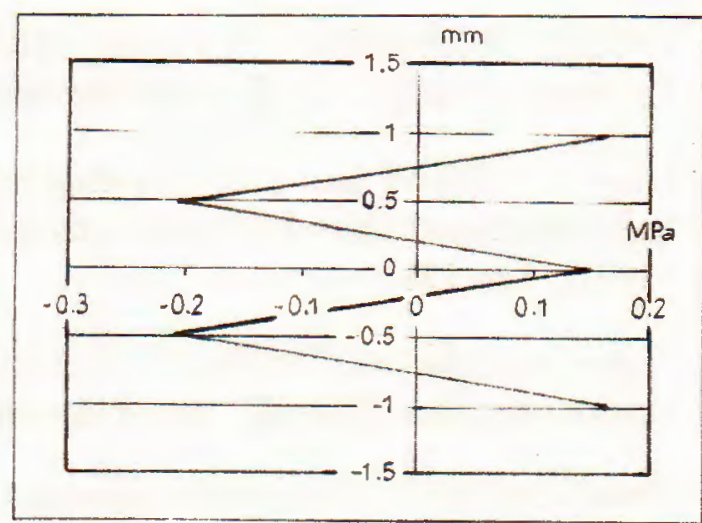

Fig. 8. Hygroscopic residual stresses $\sigma_{3}$ in thickness direction

\section{Conclusions}

Based on the governing equations, which were established by using a thirdorder displacement theory, the hygroscopic residual stresses in the cross-ply $[0 / 90]_{s}$ graphite-epoxy laminated composite were computed for two moisture content distribution profiles through the laminate thickness. The obtained numerical results show that, these stresses will depend on the moisture concentration distribution profile assumed. In practice, the moisture content profile is constant only after long period of time (about 10 years for typical $10 \mathrm{~mm}$ carbon/epoxy laminates [2]). Thus, in the initial time period, a moisture concentration is predominant in the plies near the surfaces, and zero in the inner plies about the midplane. So that, a real moisture content profile is necessary for the calculation of hygroscopic residual stresses in laminated composites. The hygroscopically induced residual stresses must be account for the strength prediction of composite materials and structures.

\section{REFERENCES}

1. Pipes R. B., Vinson J. R. and Chou T. W: On the hygrothermal response of laminated composite structures, J. of Comp. Materials, 10 (1976), 129-148.

2. Springer G. S., Environmental effects on composite materials, ed. Technomic Publishing Company. Inc. 1988.

3. Ootao Y., Tanigawa Y. et al. Transient thermal stress analysis and bending behavior of an angle-ply laminated slab. J. of Thermal Stresses 13 (1990), 177 190.

4. Benkeddad A. et al. On the transient thermal hygroscopic stresses in laminated composite plates, Composite Structure 30 (1995), 201-205. 
5. Paul A. et Vautrin A. Transient hygrothermal stresses in laminated cylinders, Proceeding of Int. Conf. Duracosys95, Brussels (1995), 281-288.

6. Chang J. S. and Leu S. Y. Thermal buckling analysis of antisymetric angle-ply laminate based on a high-order displacement field, Composite Sci. Technol, 41 (1991), 109-128.

7. Jonnaladda K. D., Tauchert T. R. and Blandford G. E. High-order thermoelastic composite plate theories. An analytical comparison, J. Thermal Stresses. 1993.

8. Tran Ich Thinh. Composite materials: Mechanics of Materials and Structures, Ed. Education, 1994 (in Vietnamese).

9. Tran Ich Thinh, Ngo Nhu Khoa. Mechanical analysis of layered composite plates. Proceedings of the sixth national congress on mechanics, Hanoi, 3-5 December 1997 (in Vietnamese).

10. Tran Ich Thinh, Ngo Nhu Khoa. Calculation of layered composite plates based on the higher-order deformation theory, Proceedings of the sixth national congress on mechanics of solids, Hanoi 11-1999 (in Vietnamese).

11. Tran Ich Thinh, Ngo Nhu Khoa. Modelling the mechanical and hygrothermal be haviour of composite laminates using a high-order displacement formulation. Proceedings of the International Colloquium in Mechanics of Solids, Fluids, Structures and Interactions. Nhatrang Vietnam, august 14-18, 2000.

Received January 16, 2001

\section{ỨNG SUẤT DƯ DO Độ ẨM GÂY RA TRONG VẬT LIỆU COMPOSITE LỚP}

Hàm ngậm å̉m chính xác $m(z, t)$ được sử dụng dể tính toán ứng suất "ẩm" dư trong vật liệu composite lớp dày. Các phương trình quan hệ được thiết lập dựa vào lý thuyết chuyển vị bậc cao đầy đư. Ứng suất dư do độ ẩm gây ra trong vật liệu composite lớp graphite/epoxy $[0 / 90]_{s}$ được so sánh với ứng suất dư tính theo giả thiết: độ ngậm ẩm $m$ là một hằng số theo suốt chiều dày của tấm vật liệu. 